\title{
PROSES PEMBERSIHAN SYNGAS HASIL GASIFIKASI TEMPURUNG KEMIRI MENGGUNAKAN SIKLON
}

\section{PROCESS OF CLEANING FOR SYNTHESIS GAS (SYNGAS) FROM CANDLENUT SHELL GASIFICATION USING A CYCLONE}

\author{
Jemseng Carles Abineno ${ }^{1 \bowtie}$, Johny Agustinus Koylal ${ }^{1}$ \\ ${ }^{1}$ Program Studi Manajemen Pertanian Lahan Kering Politeknik Pertanian Negeri Kupang \\ ${ }^{\otimes}$ Komunikasi Penulis, email : jemsengcarlesabineno@gmail.com \\ DOI:http://dx.doi.org/10.23960/jtep-lv10i1.10-15
}

Naskah ini diterima pada 2 Desember 2020; revisi pada 11 Desember 2020; disetujui untuk dipublikasikan pada 16 Desember 2020

\begin{abstract}
This study aims to examine the process of cleaning for synthesis gas (syngas) resulted from candlenut shell gasification by using a cyclone. Research was started by design or manufacture a cyclone as a tool that can condense the tar carried in the syngas produced from the gasification process. This tool was tested with by trial and error such that got a tool that can function optimally to condense tar. The syngas cleaning experiment using the cyclone was conducted by four treatments, namely S1 (1 cyclone), S2 (2 cyclones), S3 (3 cyclones), and S4 (4 cyclones). All treatments were repeated 4 (four) times, so there were 16 experimental units. The parameter measured is the amount of tar that was condensed on the cyclone. Result showed that the syngas cleaning process using a cyclone worked well, and the best treatment was $S 3$ (3 cyclones) with an average amount of condensed tar of $141.7 \mathrm{ml} / \mathrm{kg}$ of shell. The use of cyclones can condense tar and other particulates carried in the syngas. The cleaned syngas can be applied as fuel in an internal combustion engine as a substitute for diesel and gasoline fuels.
\end{abstract}

Keywords: cleaning, cyclone, gasification, syngas

\begin{abstract}
ABSTRAK
Penelitian ini bertujuan untuk mengkaji proses pembersihan synthesis gas (syngas) yang dihasilkan dari gasifikasi tempurung kemiri menggunakan siklon. Penelitian diawali dengan merancangbangun atau pembuatan siklon sebagai alat yang dapat mengkondesasi tar yang terbawa pada syngas yang dihasilkan dari proses gasifikasi. Alat ini diuji dengan prinsip trial and error hingga dihasilkan alat yang dapat berfungsi secara optimal untuk mengkondensasi tar. Proses pembersihan syngas menggunakan siklon dilakukan dengan empat perlakuan yaitu S1 (1 buah siklon), S2 (2 buah siklon), ( 3 buah siklon), dan S4 ( 4 buah siklon). Seluruh perlakuan diulang 4 (empat) kali sehingga menghasilkan 16 unit percobaan. Parameter yang diukur yaitu jumlah tar yang dapat terkondensasi pada siklon. Hasil penelitian menunjukkan bahwa proses pembersihan syngas menggunakan siklon dapat berjalan dengan baik, dan perlakuan terbaik diperoleh pada S3 (3 buah siklon) dengan jumlah tar yang dikondensasi rata-rata sebesar $141,7 \mathrm{ml} / \mathrm{kg}$ bahan. Penggunaan siklon dapat mengkondensasi tar dan partikulat lain yang ikut terbawa pada syngas. Syngas yang sudah dibersihkan dapat diaplikasikan sebagai bahan bakar pada motor bakar untuk substitusi bahan bakar solar dan bensin.
\end{abstract}

Kata Kunci: gasifikasi, pembersihan, siklon, syngas

\section{PENDAHULUAN}

Gasifikasi adalah suatu proses termokimia yang mengubah bahan bakar padat dengan proses pembakaran menggunakan oksigen terbatas (oksidasi parsial) menjadi gas mampu bakar yang dikenal dengan istilah "producer gas atau synthetis gas (syngas)". Updraft gasifier merupakan jenis gasifier yang memiliki kelebihan menghasilkan syngas yang lebih besar tetapi memiliki kekurangan karena kandungan tar dan partikulat lebih banyak (Chopra dan Jain, 2007). Penelitian yang dilakukan oleh Abineno (2012) tentang kinerja updraft gasifier 
menunjukkan bahwa kandungan tar dan partikulat masih tinggi sehingga pemanfaatan syngas hanya untuk bahan bakar proses pengeringan jagung pada sillo. Tingginya kandungan tar (254 g/kg bahan) dan partikulat ( $358 \mathrm{~g} / \mathrm{kg}$ bahan) berdampak pada hasil syngas tidak dapat diaplikasikan pada motor bakar.

Kemiri (Aleurites moluccana) merupakan tanaman dengan produktivitas 0,6 ton/ha. Pengolahan kemiri menghasilkan limbah berupa tempurung mencapai 193,36 kg/ton. Analisis nilai kalor yang terkandung dalam tempurung kemiri mencapai $0,021 \mathrm{MJ} / \mathrm{g}$, sehingga energi yang terkandung dalam tempurung kemiri sebesar $21 \mathrm{MJ} /$ ton. Namun sampai saat ini limbah tempurung kemiri tersebut belum dimanfaatkan dengan baik. Salah satu cara untuk konversi limbah tempurung kemiri adalah melalui proses gasifikasi menggunakan updraft gasifier.

Beberapa penelitian tentang pembersihan syngas telah dilakukan menggunakan updraft gasifier type hisap menunjukkan suhu nyala api rata-rata $516,7{ }^{\circ} \mathrm{C}$, kadar abu sebesar 173,16 gram, dan kadar tar yang dihasilkan 379,27 gram (Purwantana, dkk., 2013). Hasil penelitian (Abineno dan Koylal, 2017) menggunakan updraft gasifier type hembus, kadar tar dan partikulat masih tinggi yaitu ( $254 \mathrm{~g} / \mathrm{kg}$ bahan) dan partikulat (358 g/kg bahan). Hal ini menunjukan bahwa gasifikasi biomassa menggunakan updraft gasifier type hisap, dapat mengurangi kadar tar dan partikulat yang terkandung dalam syngas. Penelitian lain dilakukan oleh Nurtanio (2012) menunjukkan bahwa dengan teknologi pembersihan syngas menggunakan siklon, impinger, dan kondensator pipa spiral dapat menurunkan jumlah tar dan partikulat dalam syngas yaitu sebesar $83 \mathrm{~g} / \mathrm{m} 3$ syngas sehingga dapat diaplikasi pada motor bakar diesel. Pemilihan sistem pembersihan syngas mengurangi jumlah tar dalam syngas sebelum meninggalkan gasifier. Reforming, thermal cracking, dan steam cracking merupakan tiga reaksi utama yang dapat mengurangi jumlah tar. Proses untuk mengurangi kadar tar syngas yaitu dengan menaikkan suhu reaktor gasifier, pemasangan siklon, solvent, dan pemasangan kondensator pipa spiral.
Hasil penelitian yang dilakukan oleh (Abineno dan Koylal, 2018) menunjukkan bahwa updraft gasifier yang dirancang mampu memproduksi syngas dengan baik, namun syngas masih mengandung banyak partikulat dan tar $(173,16$ $\mathrm{g} / \mathrm{m} 3$ partikulat dan 8,20 ml tar), sehingga tidak dapat diaplikasikan ke motor bakar. Selanjutnya penelitian pemurnian syngas menggunakan scruber oleh Khairumizan (2008) menunjukkan bahwa tar dapat dipisahkan oleh burner 490 gram, setelah penggunaan scruber, mampu memisahkan tar sebanyak 320 gram, dan filter mampu memisahkan tar sebanyak 30 gram dan pada burner 70 gram. Penelitian ini bertujuan untuk mengkaji proses pembersihan gas menggunakan siklon yang dapat mengkondensasi tar dan untuk mengetahui jumlah siklon yang tepat dalam proses pembersihan tar yang terkandung pada syngas.

\section{BAHAN DAN METODE}

Penelitian ini merupakan rancangbangun alat pembersih synthesis gas (syngas) yang disebut siklon. Diagram alir pada Gambar 1 memperlihatkan rincian tahapan penelitian yang meliputi rancangbangun dan pabrikasi siklon hingga tahap pengujian gasifikasi.

Penelitian ini menggunakan updraft gasifier (Gambar 2) sebagai reaktor untuk konversi biomassa menjadi synthesis gas (syngas) tipe batch kapasitas 3,2 kg yang dilengkapi dengan perangkat instrument seperti blower, thermocouple, dan termodigital. Bahan bakar yang digunakan terdiri dari $3 \mathrm{~kg}$ tempurung kemiri dan arang pengumpan 0,2 kg sehingga total bahan bakar yang digunakan sebesar 3,2 kg. Updraft gasifier terdiri dari reaktor untuk proses pengeringan, pirolisis, pembakaran, dan reduksi (Basu, 2010). Sebuah blower tipe sentrifugal dengan putaran $2.800 /$ menit digunakan sebagai penyuplai udara ke dalam reaktor. Laju aliran udara yang digunakan dalam proses gasifikasi sebesar 462,09 l/menit (Abineno dan Koylal, 2018). Kompor dipasang sebagai komponen untuk penyalaan syngas. Setiap sampel yang diujicoba menggunakan 3 kg tempurung kemiri yang berukuran 1-2 cm dengan kadar air rata-rata 10-12\%. Penelitian ini merupakan rancangbangun alat pembersih 


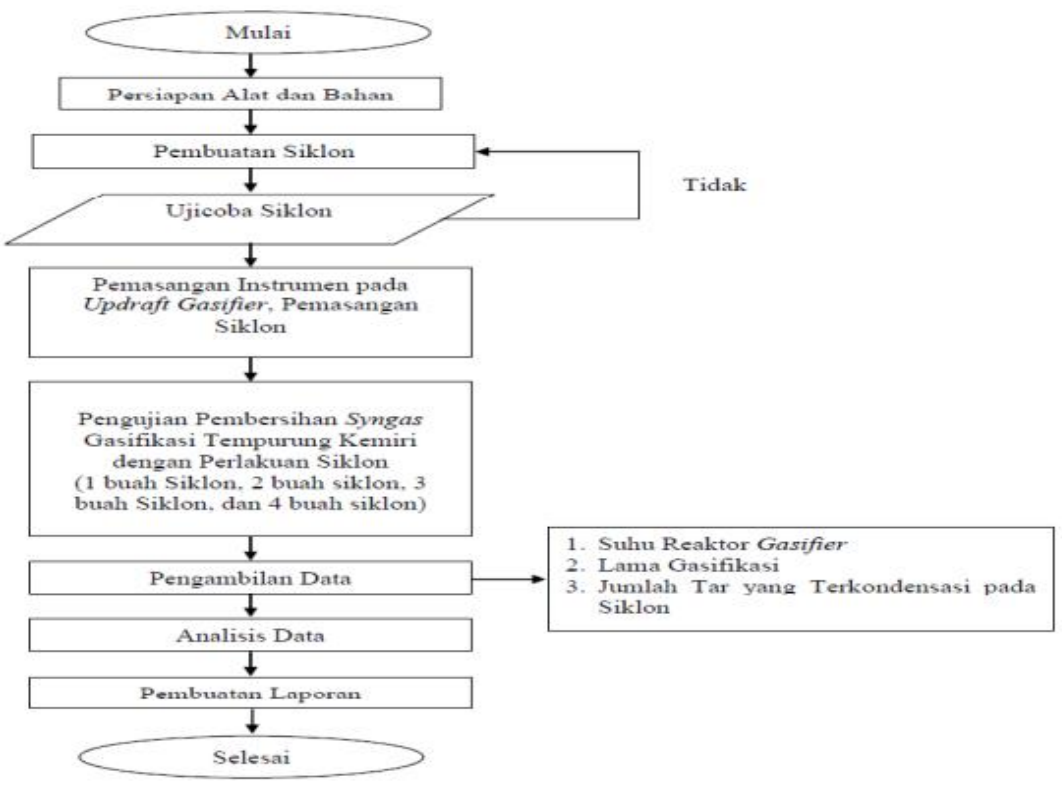

Gambar 1. Bagan Alir Tahapan Penelitian

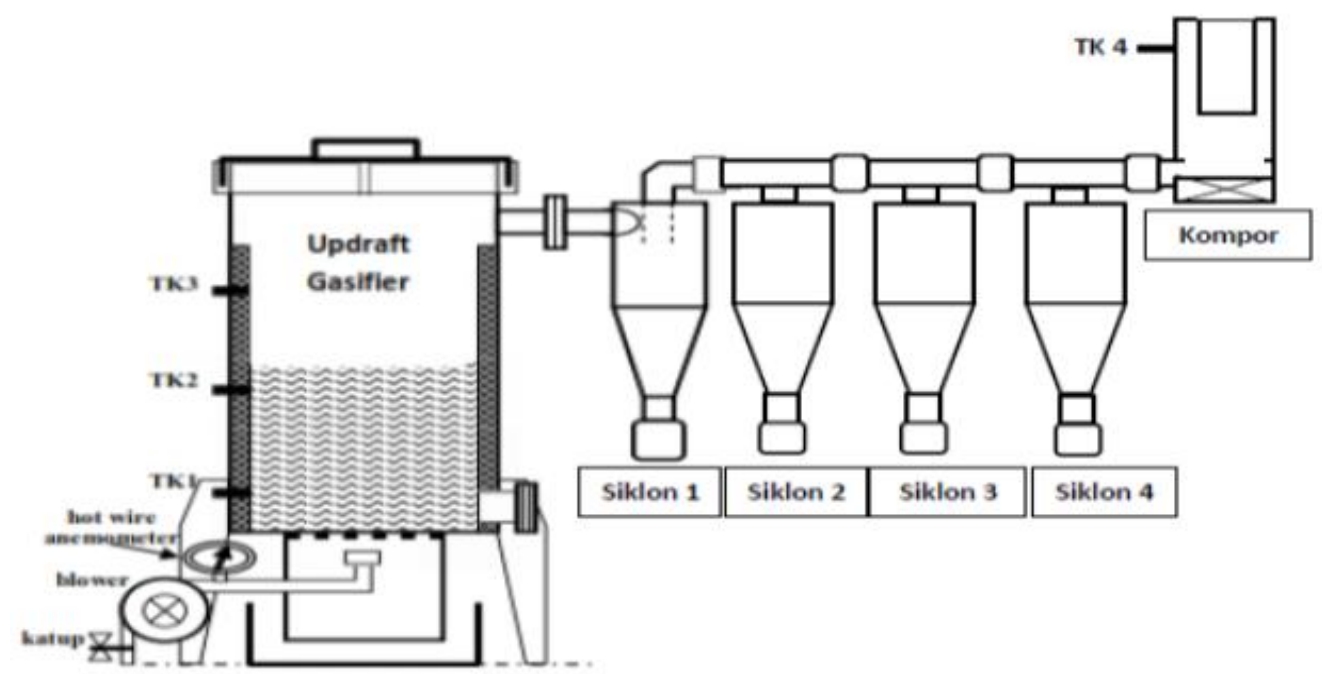

Gambar 2. Updraft Gasifier Lengkap dengan Siklon Pembersih Syngas (TK : Thermocouple)

synthesis gas (syngas) yang disebut siklon dan menghitung rata-rata tar yang terkondensasi pada siklon.

\subsection{Pengujian Gasifikasi}

Tar yang terkondensasi diambil dan diukur volumenya. Adapun pelakuan yang dicobakan adalah jumlah siklon yaitu perlakukan S1 (1 buah siklon), perlakukan S2 (2 buah siklon), perlakukan S3 (3 buah siklon), dan perlakukan S4 (4 buah siklon).

Siklon berfungsi untuk mengkondensasi tar yang terkandung pada syngas. Siklon dibuat menggunakan plat eser dengan panjang total 65 $\mathrm{cm}$, diameter over flow $15 \mathrm{~cm}$, dan diameter under flow $5 \mathrm{~cm}$. Siklon yang dibuat terdiri dari, slurry inlet, overflow, underflow, outlet tap, dan tabung aliran prymary vortex dan secondari vortex (Gambar 3).

Percobaan dilakukan dengan mengoperasikan gasifier berbahan baku tempurung kemiri sebanyak $3 \mathrm{~kg}$. Saat gasifier menghasilkan syngas, syngas akan terdisitribusi ke siklon melalului slurry inlet dan karena perbedaan tekanan maka terjadilah primary vortex dan secondary vortex. Saat terjadi primary vortex maka tar yang berkarakteristik tebal dan besar akan dikondensasi pada underflow, sedangkan partikel kecil dan halus akan ikut terbawa pada saat terjadi secondary vortex. Kemudian syngas 


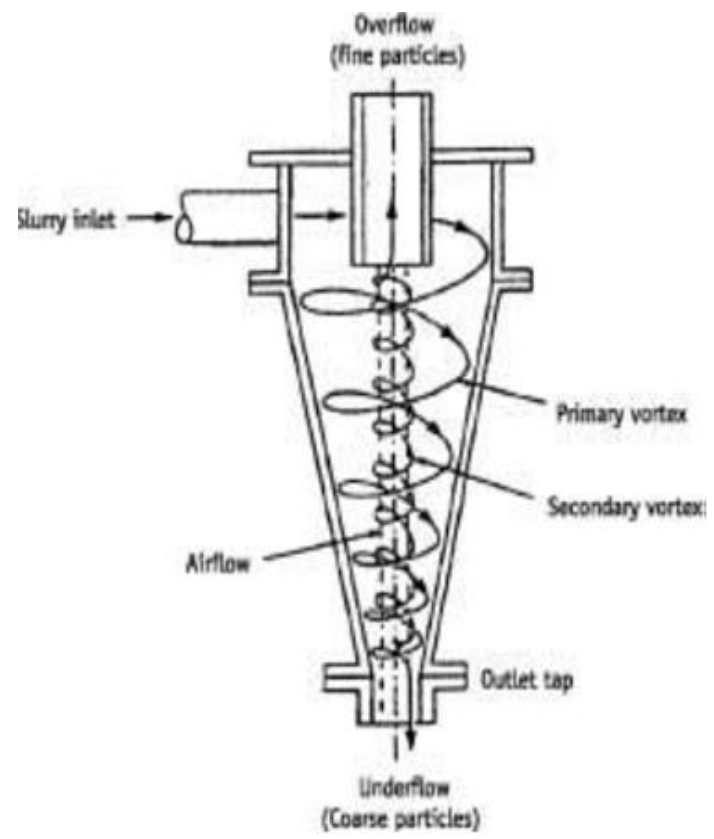

Gambar 3. Siklon (Cyclone)

akan terdistribusi pada siklon berikutnya. Tar yang tertampung pada underflow dikeluarkan lalu diukur volumenya. Pengukuran dilakukan pada seluruh siklon sesuai perlakuan.

\section{HASIL DAN PEMBAHASAN}

\subsection{Kinerja Gasifikasi}

Kinerja gasifikasi tempurung kemiri menggunakan updraft gasifier menunjukkan bahwa suhu proses gasifikasi pada ruang reaktor berada pada kisaran 300-4500C (diukur pada TK 1, TK 2, TK 3), sehingga proses pirolisis dapat terjadi. Syngas dapat menyala pada waktu ratarata 42 menit. Proses pembersihan syngas menggunakan siklon dengan berbagai jumlah siklon menunjukan bahwa siklon yang dicobakan dapat mengkondensasi tar dengan baik. Perlakuan terbaik terjadi pada perlakuan 3 buah siklon (S3) dengan rata-rata tar yang terkondensasi sebesar 141,7 ml/kg bahan.

\subsection{Jumlah Tar Terkondensasi pada Siklon}

Gambar 3, menunjukkan pada percobaan meggunakan 1 buah siklon (perlakuan S1) jumlah tar dan partikulat debu yang dapat dikondensasi oleh siklon rata-rata sebesar $96,4 \mathrm{ml} / \mathrm{kg}$ bahan $(20,96 \%)$, lalu diikuti penggunaan 2 buah siklon (perlakuan S2) rata-rata sebesar $103 \mathrm{ml} / \mathrm{kg}$ bahan $(22,42 \%)$, dan terus meningkat pada 3 buah siklon (perlakuan S3) rata-rata sebesar $141,7 \mathrm{ml} / \mathrm{kg}$ bahan (30,81\%). Pada perlakuan 4 buah siklon (perlakuan S4) tar yang terkondensasi pada siklon mengalami penurunan rata-rata sebesar $118,7 \mathrm{ml} / \mathrm{kg}$.

Tar yang dapat dikondensasi mengalami peningkatan pada $\mathrm{S} 2$ sebesar $6,6 \mathrm{ml}$ dan terus meningkat pada S3 sebesar 38,6 ml kemudian turun pada S4 (Gambar 4). Turunnya jumlah tar pada S4 diduga diakibatkan oleh semua tar yang bersifat lengket telah dikondensasi pada S1 sampai S3, dan pada S4 hanya tersisa sebagian kecil tar (partikel halus), sehingga jumlah tar yang terkondensasi makin sedikit. Hal ini dikarenakan siklon hanya dapat mengkondensasi partikel-partikel yang lebih besar dan tebal, tetapi partikel yang halus akan terus terbawa oleh syngas pada siklon berikut. Gabungan antar tar yang berkarakter lengket dan partikel yang ukurannya sangat kecil mengakibatkan hanya tar yang berkaraktek lengket saja yang dapat dikondesasi, sedangkan partikel yang ukurannya sangat kecil termasuk tetesan tar yang berukuran $1 \mu \mathrm{M}$ (Agustian, dkk. 2013).

Selain itu, turunnya jumlah tar pada S4 (4 buah siklon) disebabkan oleh tekanan dari reaktor gasifier lebih kecil dibanding tekanan pada siklon sehingga gas yang akan keluar lewat outlet gasifier tertahan oleh besarnya tekanan dari 


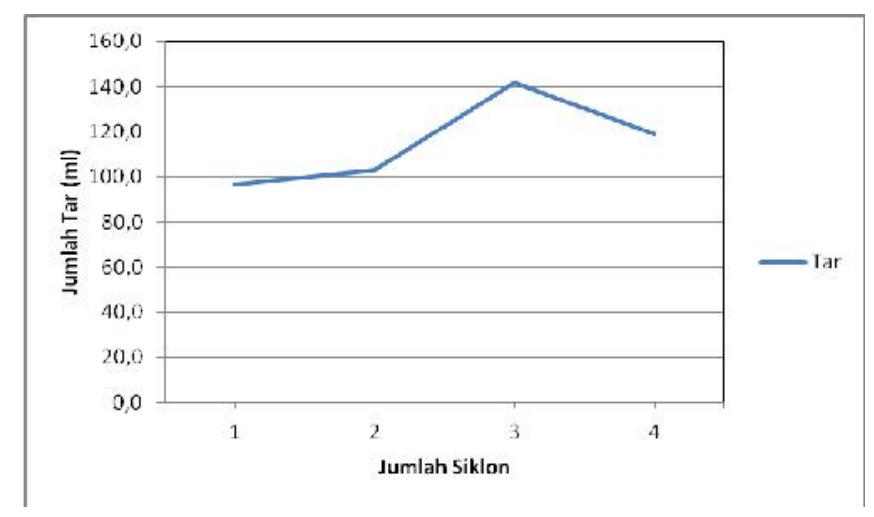

Gambar 4. Jumlah Tar yang Terkondensasi pada Siklon

siklon. Hal ini mengakibatkan syngas bersama tar akan terbakar dalam ruang oksidasi sehingga jumlah tar yang keluar ke siklon mengalami penurunan. Hal ini sesuai dengan fungsi siklon yaitu sebagai peralatan pengendali partikel yang berfungsi untuk mengumpulkan partikelpartikel halus yang terbawa dalam gas buang suatu proses dengan menggunakan titik-titik air. Pada pengolahan ini cairan umumnya air digunakan untuk menangkap partikel debu atau untuk meningkatkan ukuran aerosol.

\section{KESIMPULAN}

Hasil penelitian proses pembersihan syngas menggunakan siklon hasil gasifikasi tempurung kemiri menggunakan siklon dapat berjalan dengan baik ditandai dengan turunnya jumlah tar yang dihasilkan. Hasil tebaik terjadi pada penggunaan 3 buah siklon dengan tar terkondensasi rata-rata sebesar $141,7 \mathrm{ml} / \mathrm{kg}$ bahan.

\section{UCAPAN TERIMA KASIH}

Pusat Penelitian dan Pengabdian Masyarakat Politeknik Pertanian Negeri Kupang yang telah membiayai penelitian ini.

\section{DAFTAR PUSTAKA}

Abineno, J.C. dan Koylal, J.A. 2018. Gasifikasi tempurung kemiri sebagai energi alternatif menggunakan updaraft gasifier pada laju aliran udara berbeda. Jurnal Teknik Pertanian Lampung. 7(3):175-180.
Abineno, J.C. dan Koylal, J.A. 2017. Gasifikasi Tempurung Kemiri Menggunakan Updaraft Gasifier Type Hisap. Prosiding Seminar Ke1 Hasil-hasil Penelitian Pusat P2M. Politani Kupang. No. 1 Desember 2017: 209-213.

Abineno, J. C. 2012. Gasifikasi Tandan Kosong Kelapa Sawit menggunakan Updraft Gasifier dengan Variasi Laju Aliran Udara. Buletin Pertanian Terapan-Partner, 19(2): 09.

Agustian, C.A,_Gandidi, I. M., Burhanuddin, H. 2013. Kajian eksperimental gas cleaner yang dimodifikasi untuk mengekstrak tar dalam producer gas. Jurnal FEMA, 1(2): 73-84.

Basu, P. 2010. Biomass Gasification and Pirolisys: Practical Design. UK. Elsevier.

Chopra, S. dan Jain, A. 2007. A review of Fixed Bed Gasificatiion System for Biomass. Agricultural Engineering International: The CIGR Ejournal, IX(5).

Khairumizan, P. 2008. Studi Eksperimental Implementasi Venturi Srubber Pada Sistem Gasifikasi Batubara. Skripsi. Program Studi Teknik Mesin, Fakultas Teknik, Universitas Indonesia, Depok.

Nurtanio, I. 2012. Studi Kandungan Tar Updraft Gasifier dengan Pengeluaran Syngas pada Zona Reduksi. Skripsi. Program Studi Teknik Mesin, Fakultas Teknik, Universitas Indonesia, Depok. 
Purwantana, B., Prastowo, B., dan Abineno, J.C. 2013. Gasifikasi tandan kosong kelapa sawit menggunakan updraft gasifier. Jurnal Industri Teknologi Pertanian, 7(1): 17-20.
Ridhuan, K. dan Yudistira, Y. 2017. Pengaruh filter dan cyclone pada reaktor gasifikasi tipe updraft terhadap hasil pembakaran syngas. TURBO, 6(1): 44-53. 